\title{
An interaction model for odor quality and intensity
}

\author{
MATS J. OLSSON \\ Institute of Environmental Medicine, Karolinska Institute, Stockholm, Sweden \\ and Stockholm University, Stockholm, Sweden
}

\begin{abstract}
The perceived intensity and quality of binary odor mixtures are studied in relation to how their components are perceived when presented separately. Subjects judged the perceived intensity and quality of 6 concentrations of pyridine, 6 concentrations of $n$-butanol, and their 36 possible combinations. The results show that the perceived intensity of the mixture can be predicted from the perceived intensity of its components presented separately $\left(R_{\mathrm{A}}\right.$ and $\left.R_{\mathrm{B}}\right)$ by the Euclidian arithmetic model. The maximum probability of identifying a mixture as a "mixture" is reached when $R_{\mathrm{A}}$ and $\boldsymbol{R}_{\mathrm{B}}$ are equally strong. An interaction model for mixtures that relates perceived intensity and quality is presented and tested. The test reveals that both the perceived intensity of a mixture and the probability that it will be identified as the one or the other component can, by a simple interaction model, be successfully predicted from $R_{\mathrm{A}}$ and $R_{\mathrm{B}}$.
\end{abstract}

What do we perceive when more than one odorant is presented at the same time? Around the turn of the century, this question became quite controversial due to the substantial contributions of Zwaardemaker (1895, 1900/1959, 1907, 1930; for a review, see Olsson, 1993). He advocated that the mixture of two suprathreshold odors, even quite strong ones, are able to suppress each other to an odorless mixture when they are mixed in certain proportions. Zwaardemaker argued that this phenomenon, which he called compensation, was the olfactory analogue to how complementary colors form white light when different wavelengths are combined. However, several authors questioned the existence of compensation (e.g., Henning, 1924, 1926; Nagel, 1897; Skramlik, 1926).

Several decades later, attention was again given to odorquality interaction. The related question of whether the components are perceived in the mixture or form a new odor was revived. It has now been investigated with a number of methods, some of which imply different definitions of the problem, and the results have been diverse (e.g., Jellinek \& Köster, 1979; Laing \& Francis, 1989; Mitchell \& McBride, 1971; Moskowitz \& Barbe, 1977; Schiet \& Frijters, 1988; Schwartz, Rabin, \& Cain, 1987). Independent of the type of mixture percept, the mixture quality frequently seems to be intermediate to the quality of its component odors when presented separately (Ekman \& Engen, 1962; Gregson, 1980; Moskowitz, 1976; Moskowitz \& Barbe, 1977).

The present research was supported by grants to Birgitta Berglund from the Swedish Council for Building Research. I wish to thank Birgitta Berglund, Trygg Engen, and Åke Hellström for comments on previous versions of this manuscript, Piotr Miecznik for mathematical advice, and Armin Guhl for technical assistance. Correspondence should be addressed to Mats J. Olsson, Department of Psychology, San Diego State University, 6363 Alvarado Court, Suite 101, San Diego, CA 92120.
Typically, the hedonic value of an odor emerges in the first dimension of the odor space as revealed in a multidimensional scaling experiment, and it may be the most salient attribute of odors (B. Berglund, U. Berglund, Engen, \& Ekman, 1973; Moskowitz, 1976; Moskowitz \& Barbe, 1977; Woskow, 1968). In accordance with the perceived quality of odor mixtures, their hedonic value is also found to be intermediate to their components (Lawless, 1977; Spence \& Guilford, 1933; Lawless, 1977; cf. Dravnieks \& Jarke, 1980).

With progress in the abilities to scale odor intensity directly, a number of studies have described the quantitative principles of odor-intensity interaction. B. Berglund and Olsson (1993a) tested and reviewed four principles for both mixtures and single components: hypoadditivity, compromise, level independency, and symmetry (to be discussed later). Direct scaling methods have also allowed quite a number of models for the prediction of odor mixture intensity either from the psychophysical functions of the components or from the perceived intensities of the components (for a review, see Laffort, 1989). On the other hand, models for odor quality are few indeed (Gregson, 1986). However, some studies have dealt with both perceived intensity and quality of mixtures. For example, Laing and associates (Laing \& Francis, 1989; Laing, Panhuber, Willcox, \& Pittman, 1984; Laing \& Wilcox, 1983; see also Ekman \& Engen, 1962, and Zwaardemaker, $1900 / 1959$ ) have shown that perceived quality and perceived intensity interact. Interestingly, the ability to identify both components in a binary mixture is typically enhanced when the components, presented separately, are perceived as equally strong.

In the present study, the odor percept (i.e., the perceived intensity and quality) of a binary mixture will be examined in relation to its two component odors-that is, to the percepts of its components presented singly. This 
approach to investigating odor mixtures has been called a perceptual model, as opposed to a psychophysical model in which the odor mixture percept would be related to the physical magnitudes of the components (B. Berglund \& Olsson, 1993a; cf. Anderson, 1981, and Guilford, 1939). Moreover, subjects were asked to judge the overall intensity and quality of the mixture rather than judging the components in the mixture.

The aims were (1) to assess the quantitative principles of odor-intensity interaction in a binary mixture of two odorous substances, (2) to monitor the qualitative change of the mixture with changes in its components, (3) to explore the possibility of a relationship between perceived intensity and perceived quality, and (4) to gain some preliminary information by interview about subjects' phenomenal experience of odor mixtures.

\section{METHOD}

\section{Stimuli}

The stimuli were 6 concentrations of $n$-butanol $(296,688,1,396$, $3,100,6,852$, and $14,760 \mathrm{ppb}$ ) and 6 concentrations of pyridine $(104,174,328,562,1,002$, and $1,804 \mathrm{ppb})$, their 36 possible combinations (mixtures), and a stimulus consisting of purified air (charcoal-filtered), for a total of 49 unique stimuli. The set of 6 concentrations of each substance was selected to be approximately equal in perceived intensity as determined in a pilot experiment with 10 subjects. The stimuli ranged from perithreshold concentrations to quite strong ones. Both pyridine and $n$-butanol are commonly used in olfactory research (pyridine: Ahlström, B. Berglund, U. Berglund, Lindvall, 1986; B. Berglund, U. Berglund, Ekman, \& Engel, 1971; B. Berglund, U. Berglund, \& Lundin, 1988. n-butanol: B. Berglund, U. Berglund, \& Lindvall, 1978; Gregson, 1983; Laing, Panhuber, \& Baxter, 1978; Moskowitz, Dravnieks, \& Gerbers, 1974; Moskowitz, Dravnieks, \& Klarman, 1976.). Pyridine is sometimes referred to as "garlic-like" and unpleasant, whereas the solvent $\boldsymbol{n}$-butanol is considered less malodorous and, to some people, even pleasant (Moskowitz et al., 1974). Cain and Johnson (1978) found pyridine to be the most unpleasant odor among the 24 studied, and $n$-butanol was considered less unpleasant.

\section{Procedure}

The 19 subjects ( 10 women and 9 men), ranging in age from 20 to 43 years, were paid to take part in the experiment for 2 days. The duration of each visit was $3.5 \mathrm{~h}$. The stimuli were presented to the subjects in a hood located in a clean-air chamber (charcoalfiltered air; constant air temperature and relative humidity at $24 \pm 2{ }^{\circ} \mathrm{C}$ and $33 \pm 2 \%$, respectively). The exposure hood provided natural breathing conditions. The odor stimuli were generated by a dynamic olfactometer, described elsewhere (B. Berglund, U. Berglund, Johansson, \& Lindvall, 1986). Quick changes of stimulus concentration were accomplished by electromagnetic injection of steel capillaries of different length and bore into a main airstream of charcoal-filtered air.

The 49 stimuli were presented 10 times each in eight 15 -min sessions per day. A session contained 30-31 presentations, one presentation starting every 20-25 sec (depending on the subject's speed of responding). Each presentation lasted physically $5 \mathrm{sec}$. But, since the subjects were instructed to take just one "normal sniff," the actual exposure time was about 2 sec per sniff. A 5-min break separated the sessions, during which interval the subject was seated in an adjacent clean-air waiting room.

\section{Response Variables}

In a 10-min training session, the subjects were introduced to the odors "A" (pyridine) and "B" ( $n$-butanol), at both weak and strong levels, as well as to only background air (described henceforth as the hood). To prevent a response bias in what the subjects might have reported to be an odor mixture, they were not introduced to the physical mixtures of $\mathbf{A}$ and $\mathbf{B}$ in the training session. Before the experiment started, on each day, the subjects had to correctly identify A or B four times in a row and also two times before each session. If the subjects did not manage to identify the odors, more training was allowed until they did. The subjects were given feedback in the training session (no mixtures presented), but not during the actual experiment. The task for the subjects during the experimental sessions was first to judge the quality of the odor (single or mixture) by use of one of four response categories $(A, B, A B$, or the hood). They were to say " $A B$ "' if they perceived both $A$ and $B$ to be present simultaneously, " $A$ " or " $B$ " if they thought that only one of them was present, and "hood" if neither was there. Directly after the qualitative assessment, on the same stimulus presentation, the subjects were to scale the overall perceived intensity of the odor by the method of free-number magnitude estimation (ME; e.g., Baird \& Noma, 1978; Marks, 1974). They were also instructed to say "zero" if they found a presentation odorless. The presentations identified to be hood could be assigned a nonzero estimate if they were odorous.

\section{RESULTS}

\section{Odor Mixture Quality}

Odor-identification scales. For each of the 49 stimuli, each subject's probability of using each of the four qualitative response categories were calculated, $P(\mathrm{~A})$, $P(\mathrm{~B}), P(\mathrm{AB})$, and $P(\mathrm{H})$, where $\mathrm{H}$ represents the background air, or hood. The 19 subjects agreed fairly well on which was A and B among the odor stimuli presented to them. This is revealed by two interindividual correlation matrices (Pearson), one for the $P(A)$ values, and another for the $P(B)$ values. The correlations for the correlation matrix for $P(\mathrm{~A})$ values were median $=0.75, S D$ $=0.11$; the correlations for the correlation matrix for $P(B)$ values were median $=0.74, S D=0.14$. In both cases, $n=171$.

These response probabilities for each individual were then averaged over subjects to represent the group. The weak odors and some of their mixtures were not always distinguished from the background air. A possible confounding factor is that the subjects identified the background-air stimulus as an odor $(\mathrm{A}, \mathrm{B}$, or $\mathrm{AB})$ in $16 \%$ of the trials, and, accordingly, some of the weaker mixtures were sometimes identified as background air. Because these mixtures could be considered "qualitatively weak" and therefore different from the other stimuli, all mixtures with a $P(\mathrm{H})>.02$ were removed from the analysis. Consequently, the number of mixtures in the forthcoming analyses are reduced to 22 , instead of the full matrix of 36 mixtures.

Odor-quality interaction. In order to monitor the qualitative change of the perception of the mixture as its components are changing in intensity, the probabilities 


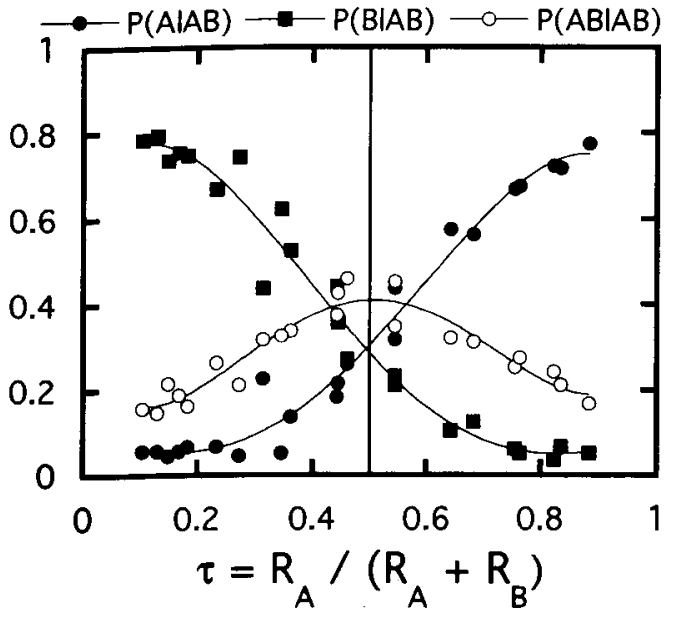

Figure 1. The probability of identifying the odor mixture (given that a mixture really was presented) as $A, B$, or $A B$ as the relative component intensity ( $\tau$ ) changes. The curves fitted are polynomials that are arbitrarily chosen to approximate data and, hence, are of no theoretical importance.

of identifying the mixtures as $\mathrm{A}, \mathrm{B}$, and $\mathrm{AB}$ were determined (Figure 1). For this purpose, a ratio of subjective values was used representing the relative component intensity $(\tau)$ introduced by Patte and Laffort (1979). The ratio provides information about the relation between the perceived intensities of the two components when presented separately $\left(\boldsymbol{R}_{\mathrm{A}}\right.$ and $\left.\boldsymbol{R}_{\mathrm{B}}\right)$ :

$$
\tau=R_{\mathrm{A}} /\left(R_{\mathrm{A}}+R_{\mathrm{B}}\right) .
$$

Three features of Figure 1 are noteworthy. First, the probabilityof identifying a mixture stimulus as A or B increases continuously, without any obvious transition points, as one component odor intensity increases relative to the other component. Note that the probability of the response " $\mathrm{AB}$," when a mixture really had been presented, $P(\mathrm{AB} \mid \mathrm{AB})$, together with $P(\mathrm{~A} \mid \mathrm{AB})$ and $P(\mathrm{~B} \mid \mathrm{AB})$ was (almost) 1. Second, $P(\mathrm{AB} \mid \mathrm{AB})$ was quite low and never reached $50 \%$ correct identification, not even for the case when equally strong components constituted the mixture. In comparison, the single odors were correctly identified in about $80 \%$ of the mixtures for the stronger odor intensities (it should be noted that these two percentages were not corrected for false alarms). Third, mixtures of equally strong components have a maximum probability of being identified as a mixture [maximum $P(\mathrm{AB} \mid \mathrm{AB})$ $\approx$.4]. Coherently, $P(\mathrm{~A} \mid \mathrm{AB})$ equals $P(\mathrm{~B} \mid \mathrm{AB})$ at that point. $P(\mathrm{~A} \mid \mathrm{AB})$ and $P(\mathrm{~B} \mid \mathrm{AB})$ are also factorially plotted in Figures $A 1$ and $A 2$ of the Appendix.

Interviews. Semistructured interviews on the perception of the odor mixtures were undertaken after the main experiment. The subjects were asked to describe their criterion for reporting the mixture percept. They were thereafter provided with two examples, presumably illustrating the principles of synthesis and analysis. For synthesis, they were asked to imagine the color orange in relation to yellow and red; for analysis, they were asked to imagine how two musical instruments sound in unison in relation to how each sounds alone. With these examples in mind, the subjects characterized what they identified to be an odor mixture.

The results of the interviews suggest that the odor mixture percept cannot be clearly distinguished from that of the single odors. This is in line with the experimental findings on probability of identification. The criterion for reporting $\mathrm{AB}$ varied between individuals. About one third of the subjects found the example of synthesis to characterize their mixture percepts. Typically, they reported $A B$ when they perceived an odor that resembled A and $B$ but was neither. Another third advocated the analytical example. The mixture percept could in this case be described to have the "full-bodied" smell of A and the "slight pungency" of B. The last third held an intermediate position. When considered together, the results of the interviews suggest that the sense of smell can range from mostly synthetic to mostly analytic, depending on the particular subject's percepts or introspective abilities. Individual differences of this type are well known in the field of perception (Vernon, 1962, p. 163), but will not be further pursued in this paper.

\section{Odor Mixture Intensity}

Odor-intensity scales. Scaling of perceived odor intensity close to the sensory threshold often results in some proportion of zero estimates. In this study, the percentage of zero estimates to odor stimuli was $6.6 \%$, and the percentage of zero estimates to background-air stimulus was $51 \%$. The decision to include these zero estimates or not and the use of the arithmetic or geometric mean in forming individual and/or group scales have been shown to have little impact on the interpretation of results from this type of experiment (B. Berglund \& Olsson, 1993a, 1993b). This is probably due to the fact that the type of mean chosen will affect both the dependent variable (the perceived intensity of the mixture) and the independent variable (the perceived intensity of the components) in much the same way.

In order to retain the information represented by zero estimates, individual scales of perceived intensity were formed by taking the arithmetic mean of each subject's 10 estimates, including the zero estimates. The individual scale was then divided by its arithmetic mean to calibrate the individual scales. The scales were then arithmetically pooled to a group scale of perceived intensity. In order to describe the agreement among the subjects, an interindividual correlation matrix (Pearson) was calculated between the individual ME scales: median $=0.89$, $S D=0.07$ (indicating a good agreement). The group scale values, $R$, will therefore be used to denote perceived odor intensity. The indices $A, B$, and $A B$ will be used to indicate what type of stimulus was presented. Power functions fit very well to the MEs of the odor intensity for 
the six concentrations $(S)$ of each substance: for pyridine, $R_{\mathrm{A}}=0.76 S_{\mathrm{A}}{ }^{0.70}\left(r_{x y}=0.997\right)$; for $n$-butanol, $R_{\mathrm{B}}=0.68$ $S_{\mathrm{B}}{ }^{0.56}\left(r_{x y}=0.999\right)$.

Odor-intensity interaction. Patte and Laffort (1979) have also introduced another useful ratio supplementary to the $\tau$ ratio (Equation 1). This ratio describes the degree of arithmetic additivity $(\sigma)$ :

$$
\sigma=R_{\mathrm{AB}} /\left(R_{\mathrm{A}}+R_{\mathrm{B}}\right) \text {. }
$$

Although from a theoretical standpoint it offers an arbitrarily selected criterion for complete additivity - that is, when $\sigma=1$ (cf. B. Berglund \& Olsson, 1993b; Frijters \& Oude Ophuis, 1983), these two ratios are useful tools in the analysis of the phenomenon of odor-intensity interaction.

Four principles of odor-intensity interaction have received special attention in previous work (B. Berglund \& Olsson, 1993a, 1993b). One principle is level independence, which suggests that the degree of additivity $(\sigma)$ will be the same for combinations of two strong odors as for two weak odors. This principle, as measured for mixtures of equally strong components $\left(R_{\mathrm{A}} \approx R_{\mathrm{B}}\right)$, has been found to apply in previous studies (B. Berglund, 1974; B. Berglund, U. Berglund, Lindvall, \& Svensson, 1973; B. Berglund \& Olsson, 1993a, 1993b; however, see Laing et al., 1984). Because the ratio between the component odor intensities is of great importance for the degree of arithmetic additivity, $\sigma$, this factor was eliminated by testing the principle of level independence on perceptually equally strong pairs of components, defined as $0.44<\tau<0.56$, which means that the stronger component is at most $25 \%$ stronger than the weaker. If level independence holds for the present data, then the perceived intensity of the mixture as a function of the sum of the perceived intensities of the component odors should be a linear function with zero intercept. As can be seen in Figure 2, the present

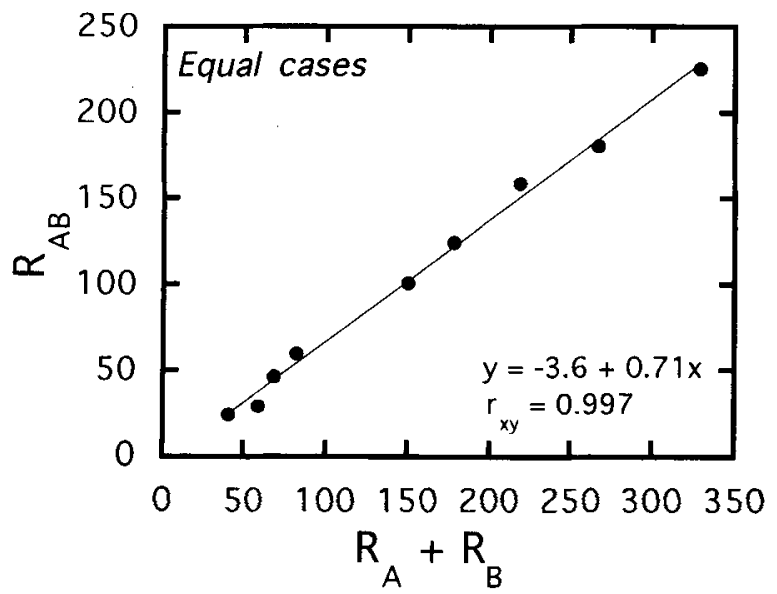

Figure 2.The odor intensity of the mixtures is plotted as a function of the sum of equally strong components $(n=9)$. The linearity and the intercept close to zero of the regression line are presumably illustrating that odor intensity interaction is level independent.

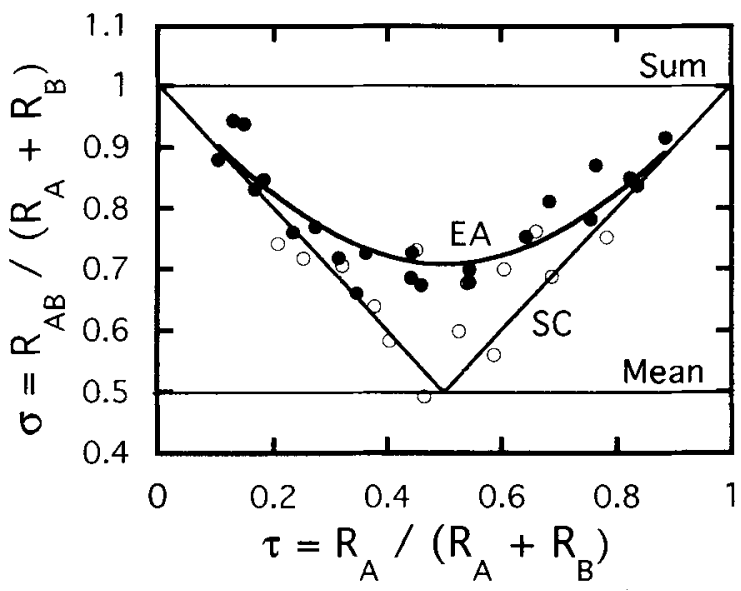

Figure 3. The degree of additivity $(\sigma)$ is plotted as a function of the relative component intensity $(\tau)$. The $U$-shaped line represents the prediction of the Euclidian additivity (EA) model. The arithmetic sum and mean and the strongest component are also drawn. Filled circles represent odor mixtures that were not confused with. the background-air stimulus on more than $2 \%$ of the trials $(n=22)$. These are therefore believed to be qualitatively stronger than the mixtures represented by open circles, which were confused with the background-air stimulus on more that $2 \%$ of the trials $(n=14)$.

data adhere well to this principle. The intercept does not deviate from zero, as revealed by a $90 \%$ confidence interval $(d f=7)$.

Another principle is hypoadditivity. Accordingly, the sum of the perceived intensities of the components exceeds the perceived intensity of the mixture-that is, $R_{\mathrm{AB}}<R_{\mathrm{A}}+R_{\mathrm{B}}$. This principle has received strong empirical support in all previous studies and is again strongly supported by the data of this study. In Figure 3 (cf. Figure $\mathrm{A} 3$ in the Appendix), the upper horizontal line represents complete additivity $\left(R_{\mathrm{AB}}=R_{\mathrm{A}}+R_{\mathrm{B}}\right)$, and the lower horizontal line represents the arithmetic mean of the component perceived intensities $\left[R_{\mathrm{AB}}=\left(R_{\mathrm{A}}+R_{\mathrm{B}}\right) / 2\right]$. The V-shaped line represents the case where the perceived odor intensity of the mixture equals that of the strongest component odor. The data show that the degree of additivity depends on the ratio between the component odor intensities. Linear combinations such as a linear multiple regression model, therefore, cannot be appropriate for the prediction of odor mixture intensity $\left(R_{\mathrm{AB}}\right)$ from the perceived intensities of the components $\left(R_{\mathrm{A}}\right.$ and $\left.R_{\mathrm{B}}\right)$. The open circles represent the aforementioned mixtures that were confused with the background-air stimulus on more than $2 \%$ of the trials $[P(H)>.02]$. These mixtures represent weaker and less discriminable odors that also display a somewhat lower additivity, which for this group of mixtures contradicts the principle of level independency.

Third, when combinations of components with $\tau$ values greater than 0.5 and less than 0.5 form odor mixtures of the same degree of additivity for the present set of data, it is called symmetry. Visual inspection of Figure 3 sug- 
gests that symmetry holds fairly well, but a slight asymmetry can be discerned. If the psychophysical function is a power function, symmetry is also the outcome expected when an odorous substance is added to itself. However, asymmetry has been observed for another combination of substances, pyridine and dimethyl disulfide, presented by B. Berglund and Olsson (1993a; cf. Laing \& Willcox, 1987). Laffort (1989) attributed this asymmetry to the difference in exponents of the psychophysical power function for the two component substances.

A fourth principle of odor-intensity interaction is the possibility that a mixture may be weaker than the strongest of its components (B. Berglund \& Olsson, 1993b; Cain, 1975; Cain \& Drexler, 1974; Köster, 1969). This is referred to as compromise (Cain \& Drexler, 1974). The act of physical addition hereby gives rise to a perceptual reduction. Gregson (1980) argued that this is the Fechner paradox commonly found for several senses. In Figure 3, the mixtures below the $\mathrm{V}$ line fit the definition of compromise, but they are also the ones that most frequently were confused with the background-air stimulus and may therefore be disregarded. This means that (almost) all of the 22 cases comply to the principle of partial addition: $R_{\mathrm{A}}+R_{\mathrm{B}}>R_{\mathrm{AB}}>R_{\mathrm{A}}>R_{\mathrm{B}}$ (B. Berglund, U. Berglund, \& Lindvall, 1976; Cain \& Drexler, 1974).

From the slope of the function shown in Figure 2, it can be seen that the perceived intensity of the mixture is $71 \%$ of the sum of the equally strong components (if the intercept is disregarded). It would mean that the degree of arithmetic additivity for equally strong components is 0.71 . Interestingly, this degree of additivity for equal cases coincides with a special case of the vector model (B. Berglund et al., 1973), later called the euclidean additivity (EA) model by Laffort and Dravnieks (1982):

$$
R_{\mathrm{AB}}=\left(R_{\mathrm{A}}^{2}+R_{\mathrm{B}}^{2}\right)^{1 / 2} \text {. }
$$

As shown in Figure 3, the EA model approximates the present (reduced) set of data very well. The hypoadditivity of the EA model depends on the ratio between the components $(\tau)$ in the same way as exhibited in the empirical data. Consequently, the characteristics of the EA model are in concordance with the empirical data. The EA model shows hypoaddition, symmetry, and level independence, and it does not show evidence of compromise.

\section{A Model for Qualitative and Quantitative Odor Interaction}

In the following, an interaction model is described that relates odor intensity to odor quality. The interaction model is based on the EA model (Equation 3). As shown above, the EA model predicts very accurately the odor intensity of the mixtures from the perceived intensities of the components, as is also obvious from Figure 4. The second crucial observation for the interaction model is seen in Figure 1. The probability of identifying a mixture as either A or B is symmetrically related to the perceived intensity of the components presented separately and, specifically, that $P(\mathrm{~A} \mid \mathrm{AB})$ equals $P(\mathrm{~B} \mid \mathrm{AB})$ when the component odors are equally strong.

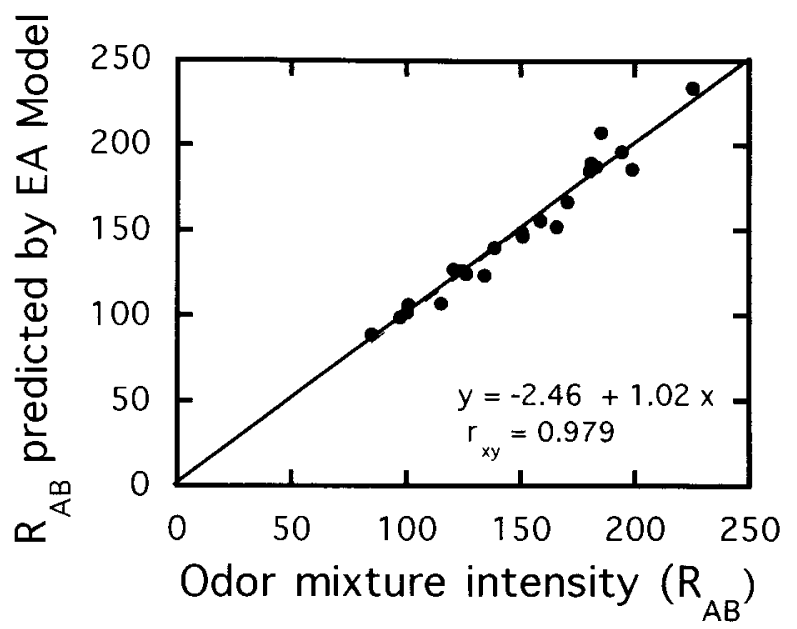

Figure 4. The perceived odor mixture intensity as predicted by the Euclidian arithmetic model is plotted as a function of the empirical $(n=22)$.

Because the data clearly show that the qualitative dominance of either component in the mixture shifts at $R_{\mathrm{A}}=$ $R_{\mathrm{B}}$, the model is designed to do the same. However, because the qualitative shifting points between the mixture $(\mathrm{AB})$ and the components (A and $\mathrm{B})$ might be of more arbitrary nature, $P(\mathrm{AB} \mid \mathrm{AB})$ is not modeled. Therefore, $P(\mathrm{~A} \mid \mathrm{AB})$ and $P(\mathrm{~B} \mid \mathrm{AB})$ will be weighted as if the response category $\mathrm{AB}$ was not allowed. For each mixture, $P(\mathrm{AB} \mid \mathrm{AB})$ is added proportionally to $P(\mathrm{~A} \mid \mathrm{AB})$ and $P(\mathrm{~B} \mid \mathrm{AB})$. These new variables are defined accordingly: $P(\mathrm{a})=P(\mathrm{~A} \mid \mathrm{AB})$ $/[P(\mathrm{~A} \mid \mathrm{AB})+P(\mathrm{~B} \mid \mathrm{AB})]$, and $P(\mathrm{~b})=P(\mathrm{~B} \mid \mathrm{AB}) /[P(\mathrm{~A} \mid \mathrm{AB})$ $+\mathrm{P}(\mathrm{B} \mid \mathrm{AB})]$. In the following text, these new variables will be referred to as the "empirical $P(\mathrm{a})$ and $P(\mathrm{~b})$," even though they are inferred from empirical data.

In Figure 5, the quality-intensity interaction model is graphically illustrated by two examples. The left-hand figure shows the interaction model when $R_{\mathrm{A}}=R_{\mathrm{B}}$, and the right-hand figure shows the interaction model when $R_{\mathrm{A}}<$

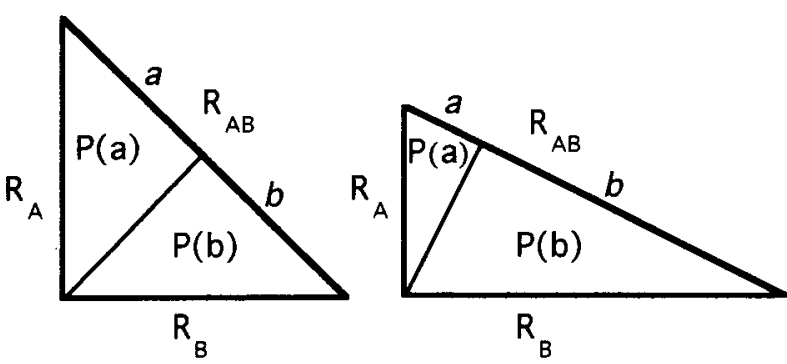

Figure 5. An interaction model for relating odor intensity to odor quality. $\boldsymbol{R}_{\mathrm{AB}}$ is the perceived intensity of a mixture of odor $A$ and $B ; R_{A}$ and $R_{B}$ are the perceived odor intensity of the components $A$ and $B$, respectively. $P(a)$ and $P(b)$ are the empirical (see text) probabilities for identifying a mixture as $A$ and $B$, respectively. The $a$ and $b$ are the odor intensity contributions of the components to the odor intensity of the mixture. The left-hand figure illustrates the case when $\boldsymbol{R}_{\mathrm{A}}=\boldsymbol{R}_{\mathrm{B}}$ whereas the right-hand figure represent the case when $\boldsymbol{R}_{\mathrm{A}}<\boldsymbol{R}_{\mathrm{B}}$. 
$R_{\mathrm{B}}$. The component intensities $\boldsymbol{R}_{\mathrm{A}}$ and $\boldsymbol{R}_{\mathrm{B}}$ are projected onto the hypotenuse $R_{\mathrm{AB}}$. These projections ( $a$ and $b$ ) represent the odor intensity contribution of the components to the mixture and are strictly theoretical constructs. The line separating $P(a)$ from $P(b)$ is always perpendicular $\left(90^{\circ}\right)$ to $R_{\mathrm{AB}}$.

The interaction model predicts the perceived quality and intensity of the mixture [i.e., $P(\mathrm{a}), P(\mathrm{~b})$, and $R_{\mathrm{AB}}$ ] from the perceived intensity of the two components presented separately $\left(R_{\mathrm{A}}\right.$ and $\left.R_{\mathrm{B}}\right)$ in the following manner. First, the odor intensity of the mixture, $R_{\mathrm{AB}}$, is predicted from the odor intensity of the two components, $R_{\mathrm{A}}$ and $R_{\mathrm{B}}$, according to Equation 3 (cf. Figure 4). The projections $a$ and $b$ can then be calculated such that

$$
a=R_{\mathrm{A}}^{2} / R_{\mathrm{AB}} \text { and } b=R_{\mathrm{B}}^{2} / R_{\mathrm{AB}} \text {. }
$$

To show how the probability of identification is proportional to the odor-intensity contribution of the components, the predicted $P(a)$ and $P(b)$ could be defined

$$
\begin{gathered}
P(\mathrm{a})=a /(a+b) \text { and } \\
P(\mathrm{~b})=b /(a+b) .
\end{gathered}
$$

A direct and simple way to estimate the size of these probabilities is the following:

$$
\begin{gathered}
P(\mathrm{a})=R_{\mathrm{A}}^{2} /\left(R_{\mathrm{A}}^{2}+R_{\mathrm{B}}^{2}\right) \text { and } \\
P(\mathrm{~b})=R_{\mathrm{B}}^{2} /\left(R_{\mathrm{A}}^{2}+R_{\mathrm{B}}^{2}\right) .
\end{gathered}
$$

In Figure 6 , it is first of all noteworthy that $P(a)$ and $P(b)$ have the same symmetrical relation as do $P(\mathrm{~A} \mid \mathrm{AB})$ and $P(\mathrm{~B} \mid \mathrm{AB})$ in Figure 1 . Second, the concordance between the $P(\mathrm{a})$ and $P(\mathrm{~b})$ predicted by the interaction model (Equation 6; represented by filled symbols and broken

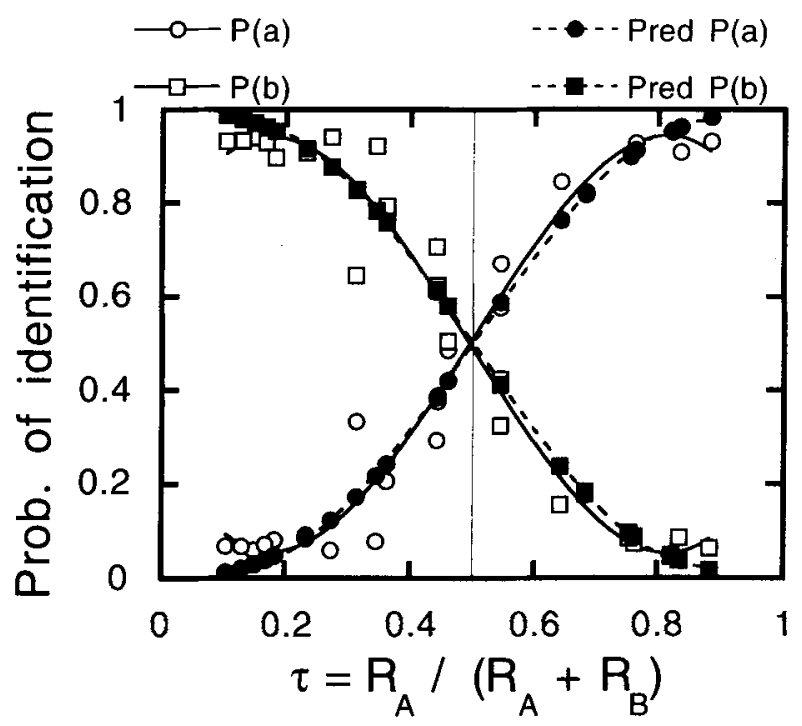

Figure 6. Empirical $P(a)$ and $P(b)$ (open symbols and solid line) and the preticted $P(a)$ and $P(b)$ (filled symbols and broken line) from the model (Equation 6) as a function of the relative component intensity. The functions fitted are polynomials and are of no theoretical importance.

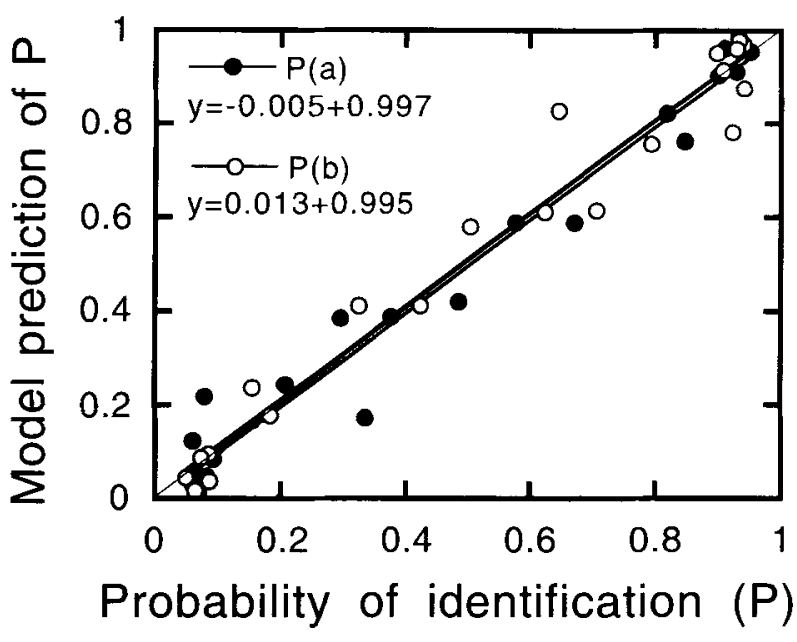

Figure 7. The predicted $P(a)$ and $P(b)$ from Equation 6 in relation to the empirical. Filled symbols represent odor $\mathbf{A}$ (pyridine), and open symbols represent odor $B$ (n-butanol). The thin lines refer to the equations fitted to the two sets of data points.

lines) and the empirical $P(a)$ and $P(b)$ (open symbols and solid lines) is obvious. In order to see if there is any systematic difference between the predicted and empirical values, they were plotted against each other in Figure 7. The regression lines adhere well to the identity diagonal, implying that the interaction model accurately predicts the probability of identifying the odor quality of a mixture from the odor intensity of the components. It should be noted from Figures 6 and 7 that the prediction of one probability depends on the prediction of the other, such that $P(a)=1-P(b)$.

As already noted, the EA model does not just predict the odor intensity of the mixtures accurately. It also conforms to those principles that describe the empirical data, hypoaddition, level independency, symmetry, and partial addition (noncompromise). The interaction model, being an extension of the EA model, will therefore have some properties in common with it. The principles of level independency and symmetry are theoretically applicable to odor quatity. To be qualitatively level independent, $P(a)$ and $P(b)$ for any component intensities $\left(R_{\mathrm{A}}\right.$ and $\left.R_{\mathrm{B}}\right)$ must remain the same when the component odor intensities are increased by any positive factor. That is, if two substances with the perceived intensities $R_{\mathrm{A}}=3$ and $R_{\mathrm{B}}=4$ are combined into a mixture, then the interaction model (Equation 6) would predict $P(a)$ to be 0.36 , which would also be the result if the odor component intensities were doubled, or tripled. For symmetry to be a valid principle for the odor quality of the mixture, reversing the component intensities (i.e., $R_{\mathrm{A}}=4$ and $R_{\mathrm{B}}=3$ ) would give the same value for $P(\mathrm{~b})$ as for $P(\mathrm{a})$ in the above example [i.e., $P(\mathrm{~b})$ $=0.36]$. Accordingly, the fit of the interaction model may serve as a tentative test of whether these two principles are valid also for the quality of odor mixtures (see Figures 6 and 7). Specifically, symmetry is the prevailing impression of the results in Figure 6. 


\section{DISCUSSION}

Odor perception is generally associated with an accurate discrimination of quality, although the existence of formal evidence is scarce. Odor identification, on the other hand, also requires an association between the odor and its label and may therefore be less accurate (Cain, 1988). For example, Engen and Pfaffman (1960) showed that the channel capacity for odors of different quality is only about four bits of information (16 odors), which is approximately what one finds for other modalities (Engen, 1991, p. 78).

For two reasons, the task of the subjects in this study was not that of an ordinary quality discrimination or odor identification. First, in addition to discriminating between odors A and B at different intensity levels, the subjects must also decide what is to be called a mixture. It should be remembered that the subjects were not provided with mixture examples by the experimenter or with feedback about their performance during the experiment. Second, the mixtures were designed to range from largely containing the one odor to largely containing the other, thereby preventing the subjects from experiencing three "clear-cut" categories of odor quality. In addition, it is well known that masking occurs when one odor is sufficiently stronger than the other (e.g., Cain, 1975; Cain \& Drexler, 1974; Mitchell \& McBride, 1971; Zwaardemaker, 1930), but how the perceived quality of the masking stimulus is affected is not known. This, of course, is confusing to the subjects, who sometimes showed less confidence and accuracy later in the experiment than in the beginning.

In this study, odor quality has been quantified in terms of the probability of identification. This does not mean that the probabilities are a measure of metric similarity on a dimension going from quality A to B (cf. Ekman \& Engen, 1962; Ekman, Engen, Künnapas, \& Lindman, 1964). At least for a synthetic sense of smell, it is theoretically possible for a mixture percept to be very dissimilar to its components. If that is the case for the present data, these mixtures in Figures 1 and 6, which seem to have a quality intermediate to their components, may in fact be more dissimilar to their components than the components are dissimilar to each other. However, the research referred to above on other substance combinations as well as the interviews of this study suggest that the mixture percept did not form a quality that is dissimilar to the quality of its component odors, but rather one that falls in between. One may conclude for this set of data, that interpretations concerning the nature of the similarity between mixtures and components cannot be done in terms other than those of probability of identification.

The perceptual approach to odor-mixture research provides a fruitful framework for odor interaction. That the percept of odor mixtures is related in a systematical and simple way to the perceived intensity of the components when presented separately gives credit to the thoughts ex- pressed by Algom and Cain (1991). They asked subjects to mentally mix both perceived and imagined odors with regard to odor intensity. These mental operations agreed well with the actual estimates of the mixtures. The authors state that "people carry an underlying core of ecologically valid chemosensory knowledge," and "most likely, the source of the observed congruence in the results of the perceptual and mental tasks lies in a common cognitive algebra (cf. Anderson, 1981, 1982) or olfactory integration" (Algom \& Cain, 1991, p. 1116).

To summarize, a perceptual interaction model has been suggested that successfully relates perceived intensity and quality of mixtures to perceived odor intensity of components. The model was developed in accordance with the results and principles revealed and reviewed in this study. However, the results of earlier studies with other combinations of odorants imply that the suggested interaction model would overestimate the general degree of additivity for these mixtures. This suggests that the model should be generalized to be able to express a variable degree of additivity in analogy to the vector model. However, generalization of the model to mixtures with variable degree of additivity, as well as to mixtures of more than two components, would be better accomplished in relation to such data and with diverse methods of measurement of perceived intensity and quality.

\section{REFERENCES}

Ahlström, R., Berglund, B., Berglund, U., \& Lindvall, T. (1986). Formaldehyde odor and its interaction with the air of a sick building. Environment International, 12, 289-295.

Algom, D., \& CAIN, W. S. (1991). Remembered odors and mental mixtures: Tapping reservoirs of olfactory knowledge. Journal of Experimental Psychology: Human Perception \& Performance, 17, 1104-1119.

ANDERSON, N. H. (1981). Foundations of information integration theory. New York: Academic Press.

ANDERSON, N. H. (1982). Methods of information integration theory. New York: Academic Press.

BAIRD, J. C., \& NomA, E. (1978). Fundamentals of scaling and psychophysics. New York: Wiley-Interscience.

BERGLUND, B. (1974). Quantitative and qualitative analysis of industrial odors with human observers. Annals of the New York Academy of Sciences, 237, 35-51.

Berglund, B., Berglund, U., Ekman, G., \& Engen, T. (1971). Individual psychophysical functions for 28 odorants. Perception \& Psychophysics, 9, 379-384.

Berglund, B., Berglund, U., Engen, T., \& Ekman, G. (1973). Multidimensional analysis of twenty-one odors. Scandinavian Journal of Psychology, 14, 131-137.

Berglund, B., Berglund, U., Johansson, I., \& Lindvall, T. (1986). Research equipment for sensory air quality studies of nonindustrial environments. Environment International, 12, 189-194.

Berglund, B., Berglund, U., \& Lindvall, T. (1976). Psychological processing of odor mixtures. Psychological Review, 83, 432-441.

Berglund, B., Berglund, U., \& Lindvall, T. (1978). Separate and joint scaling of perceived odor intensity of $n$-butanol and hydrogen sulfide. Perception \& Psychophysics, 23, 313-320.

Berglund, B., Berglund, U., Lindvall, T., \& Svensson, L. T. (1973). A quantitative principle of perceived intensity summation in odor mixtures. Journal of Experimental Psychology, 100, 29-38.

Berglund, B., Berglund, U., \& Lundin, L. (1988). Odor reduction 
by biological soil filters. In R. Perry \& P. W. Kirj (Eds.), Indoor and ambient air quality (pp. 410-419). London: Selper.

Berglund, B., Olsson, M. J. (1993a). Odor-intensity interaction in a binary mixture. Journal of Experimental Psychology: Human Perception \& Performance, 19, 302-314.

Berglund, B., Olsson, M. J. (1993b). Odor-intensity interaction in binary and ternary mixtures. Perception \& Psychophysics, 53, 475-482.

CAIN, W. S. (1975). Odor intensity: Mixtures and masking. Chemical Senses \& Flavour, 1, 339-352.

CAIN, W. S. (1988). Olfaction. In R. C. Atkinson, R. J. Herrnstein, G. Lindzey, \& R. D. Luce (Eds.), Stevens' Handbook of experimental psychology: Vol 1. Perception and motivation (pp. 409-459). New York: Wiley.

CaIN, W. S., \& Drexler, M. (1974). Scope and evaluation of odor counteraction and masking. Annals of the New York Academy of Sciences, 237, 427-439.

CAIN, W. S., \& JohnSon, F., JR. (1978). Lability of odor pleasantness: Influence of mere exposure. Perception, 7, 459-465.

DravniEKS, A., \& JARKE, F. (1980). Hedonic values of odor mixtures as functions of hedonic values of their components. In $\mathrm{H}$. van der Starre (Ed.), Olfaction and taste VII (pp. 393-396). London: IRL Press.

EXMAN, G., \& ENGEN, T. (1962). Multidimensional ratio scaling and multidimensional similarity in olfactory perception (Reports from the Psychological Laboratory, Stockholm University, No. 126). Stockholm: Stockholm University.

Ekman, G., Engen, T., Künnapas, T., \& Lindman, R. (1964). A quantitative principle of qualitative similarity. Joumal of Experimental Psychology, 68, 530-536.

ENGEN, T. (1991). Odor sensation and memory. London: Praeger.

Engen, T., PFaffmann, C. (1960). Absolute judgments of odor quality. Journal of Experimental Psychology, 59, 214-219.

Frutters, J. E. R., \& Oude Ophuis, P. A. M. (1983). The construction and prediction of psychophysical power functions for the sweetness of equiratio sugar mixtures. Perception, 12, 753-767.

GREGSON, R. A. (1980). A model of paradoxical odour mixture perception. Chemical Senses, 5, 257-269.

GREGSON, R. A. (1983). The sequential structure of odor mixture component intensity judgments. British Journal of Mathematical \& Statistical Psychology, 36, 132-144.

Gregson, R. A. (1986). Qualitative and aqualitative intensity components of odour mixtures. Chemical Senses, 11, 455-470.

Guilforo, J. P. (1939). A study in psychodynamics. Psychometrica, 4, 1-23.

Henning, H. (1924). Der Geruch (2nd ed.). Leipzig: Johann Ambrosius Barth.

Henning, H. (1926). Physiologische Studien an Geruchsinn. In E. Abderhalden (Ed.), Handbuch der Biologischen Arbeitsmethoden (Vol. 6A, pp. 741-836). Berlin: Urban \& Schwarzenberg.

Jellinek, J. S., \& Köster, E. P. (1979). Perceived fragrance complexity and its relationship to familiarity and pleasantness. Journal for the Society of Cosmetical Chemistry, 30, 253-262.

Köster, E. P. (1969). Intensity in mixtures of odorous substances. In C. Pfaffmann (Ed.), Olfaction and taste (Vol 3, pp. 142-149). New York: Rockefeller University Press.

LAFFORT, P. (1989). Models for describing intensity interactions in odor mixtures: A reappraisal. In D. G. Laing, W. S. Cain, R. L. McBride, \& B. W. Ache (Eds.), Perception of complex smells and tastes (pp. 173-188). New York: Academic Press.

LAFForT, P., \& DRAVNieks, A. (1982). Several models of suprathreshold quantitative olfactory interaction in humans applied to binary, ternary, and quaternary mixtures. Chemical Senses, 7, 153-174.

Laing, D. G., Francis, G. W. (1989). The capacity of humans to identify odors in mixtures. Physiology \& Behavior, 46, 809-814.
LaIng, D. G., Panhuber, H., \& BaXter, R. I. (1978). Olfactory properties of Amines and $n$-Butanol. Chemical Senses \& Flavour, 3, 149-165.

Laing, D. G., Panhuber, H., Willcox, M. E., \& Pittman, E. A. (1984). Quality and intensity of binary odor mixtures. Physiology \& Behavior, 33, 309-319.

LAING, D. G., \& WillcoX, M. E. (1983). Perception of components in binary odor mixtures. Chemical Senses, 7, 249-264.

LAING, D. G., \& WiLlcox, M. E. (1987). An investigation of the mechanisms of odor suppression using physical and dichorhinic mixtures. Behavioural Brain Research, 26, 79-87.

LAWLESS, H. T. (1977). The pleasantness of mixtures in taste and olfaction. Sensary Process, 1, 227-237.

MARKs, L. E. (1974). Sensory processes: The new psychophysics. London: Academic Press.

Mitchell, M. J., \& McBRIDE, R. L. (1971). Effects of propanol masking odor on the olfactory intensity scaling of eugenol. Journal of Experimental Psychology, 87, 309-313.

Moskowitz, H. R. (1976). Multidimensional scaling of odorants and mixtures. Lebensmittelwissenschaft und Technologie, 9, 232-238.

Moskowitz, H. R., BARBE, C. D. (1977). Profiling of odor components and their mixtures. Sensory Processes, 1, 212-226.

Moskowitz, H. R., Dravnieks, A., Gerbers, C. (1974). Intensity and pleasantness of Butanol. Joumal of Experimental Psychology, 103, 216-223.

Moskowitz, H. R., Dravnieks, A., \& Klarman, L. A. (1976). Odor intensity and pleasantness for a diverse set of odorants. Perception \& Psychophysics, 19, 122-128.

NAGEL, W. A. (1897). Über Mischgerüche und die Komponentengliederung des Geruchsinnes. Zeitschrift für Psychologie und Physiologie der Sinnesorgane, 15, 82-101.

OLsson, M. J. (1993). The perception of odors in interaction. Stockholm: Stockholm University, Department of Psychology.

PATTE, F., \& LAFFORT, P. (1979). An alternative model of olfactory quantitative interaction in binary mixtures. Chemical Senses \& Flavour, 4, 267-274.

SChieT, F. T., \& FriJters, J. E. R. (1988). An investigation of the equiratio-mixture model in olfactory psychophysics: A case study. Perception \& Psychophysics, 44, 304-308.

Schwartz, A. L., Rabin, M. D., \& Cain, W. S. (1987). Perceptual separability and integrality in odor discrimination. Annals of the New York Academy of Sciences, 510, 595-596.

SKRAMLIK, E. VON (1926). Handbuch der Physiologie der niederen Sinne: Vol. 1. Die Physiologie des Geruchs und Geschmacksinnes. Leipzig: Georg Thieme Verlag.

SPENCE, W., \& GuILFORD, J. P. (1933). The affective value of combination of odors. American Journal of Psychology, 45, 495-501.

VERNON, M. D. (1962). The psychology of perception. Middlesex, UK: Penguin.

Woskow, M. H. (1968). Multidimensional scaling of odors. In N. Tanyolac (Ed.), Theories of odors and odor measurement (pp. 147191). London: Technivision.

ZwaArdemaker, H. (1895). Physiologie des Geruches, Leipzig: Engelmann.

ZwAARDEMAKER, H. (1900). Die Compensation der Genuchsempfindungen. Archiv für Anatomie und Physiologie (Physiol. Abteilung), 423-432. [Translated: Smell compensation. Perfumery \& Essential Oil Record, 1959, 50, 217-221.]

ZwaARDEmaker, H. (1907). Über die Proportionen der Geruchskompensation. Archiv für Anatomie und Physiologie (Physiol. Abteilung), 31 (Suppl.), 59-70.

Zwaardemaker, H. (1930). Prüfung des Geruchsinnes und der Gerüche. In E. Abderhalden (Ed.), Handbuch der Biologischen Arbeitsmethoden (Vol. 7, pp. 455-522). Berlin: Urban \& Schwarzenberg. 
APPENDIX

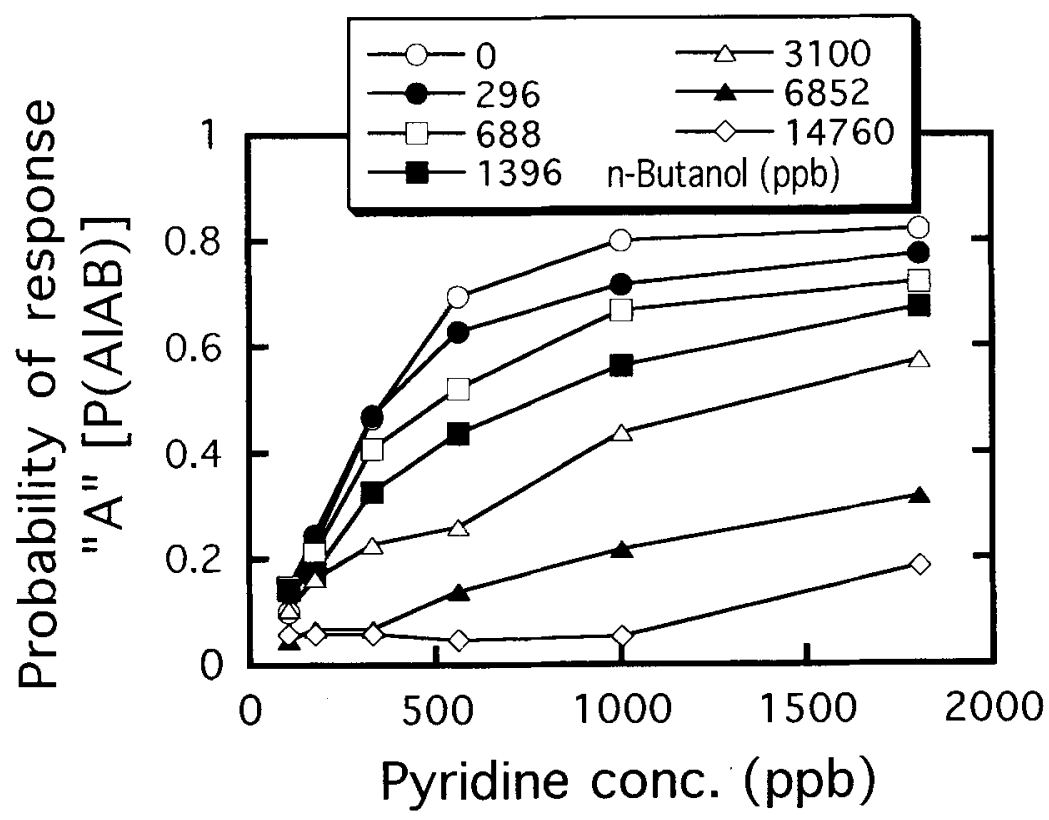

Figure A1. The probability of identifying an odor mixture to be a pyridine stimulus (A) is shown as a function of pyridine concentration for different concentrations of $n$ butanol as the second component.

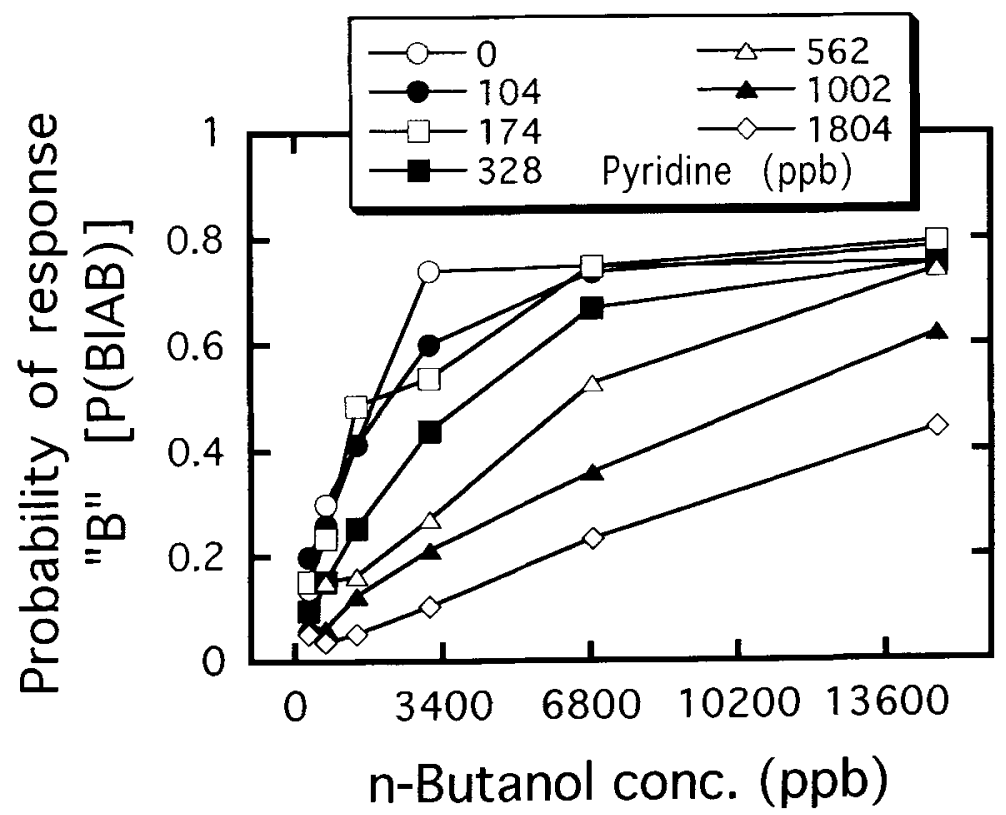

Figure A2. The probability of identifying an odor mixture to be an $n$-butanol stimulus $(B)$ is shown as a function of $n$-butanol concentration for different concentrations of pyridine as the second component. 


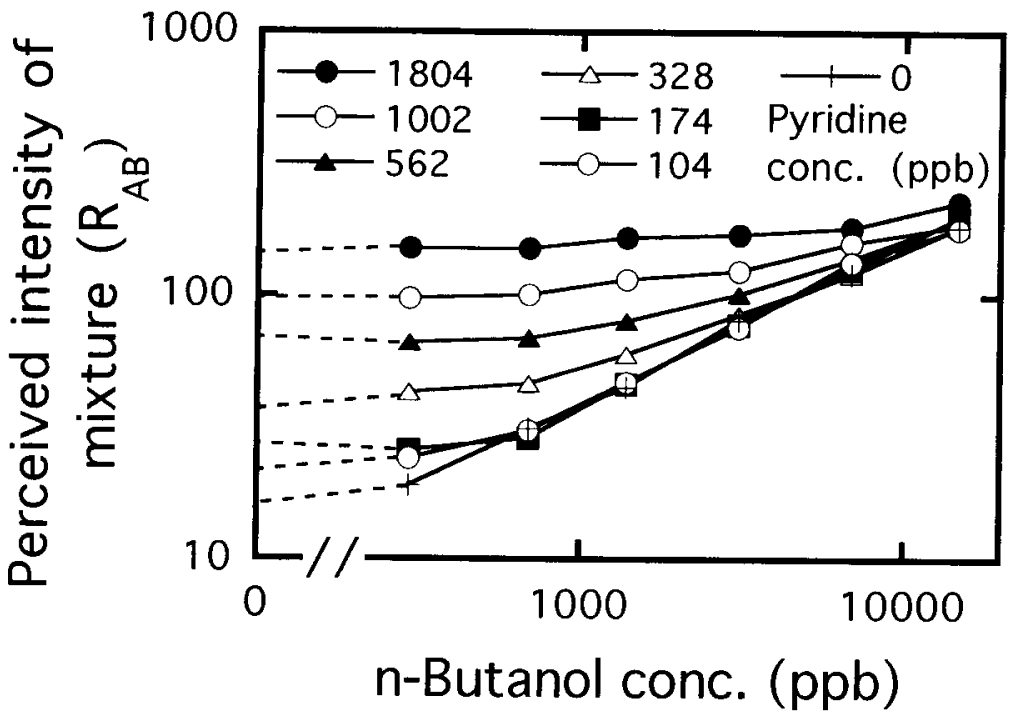

Figure A3. The perceived intensity of the mixture $(\log )$ is shown as a function of $n$-butanol concentration (log) for different concentrations of pyridine as the second component.

(Manuscript received Feburary 23, 1993 ;

revision accepted for publication August 10, 1993.) 